\title{
Museus-Casas: Um Olhar Fenomenológico.
}

\author{
Ana Christina Vieira Zarco Câmara Anita ${ }^{1}$
}

\begin{abstract}
Resumo
O objetivo da comunicação é elaborar, tendo em vista a espacialidade própria aos museus-casas, uma investigação de caráter fenomenológico. Tal caráter se desvela através da consideração de todo e qualquer objeto como dotado de uma infinidade de significações, que somente se delimitam no instante em que este entra em relação. Nosso ponto de partida é a duplicidade do objeto "museu-casa": enquanto objeto voltado para o habitante da casa e suas construções de sentido; e enquanto objeto voltado para o olhar e as expectativas do visitante da casa, daquele que perscruta a fronteira movediça e intangível, que separa e reúne tempos, espaços e significâncias tecidas pela relação casa-morador-visitante.

É sabida a impossibilidade de se reconstruir com fidelidade absoluta e inconteste a "aura" da casa de outros tempos, assim como sabe-se da atual tendência a afastar o objetivo do museu-casa de tais pretensões. A ausência dos moradores e o deslocamento espaço-temporal são alguns dos fatores que impedem um olhar direto à casa per se. Apesar deste distanciamento tomado da casa em sua dinâmica própria, há um fator considerado privilegiado quando se trata das relações entre os ambientes re-encenados e o visitante, por concernir ao próprio do museu-casa: a intimidade evocada. Aquilo que diferencia o museu-casa de outros museus e que estimula, no visitante, uma receptividade peculiar, a saber, a curiosidade por conhecer, ainda que deslocados de seu espaço-tempo e movimento próprios, os espaços secretos de
\end{abstract}

\footnotetext{
${ }^{1}$ Professora adjunta da Universidade Federal Fluminense - Rio de Janeiro, Brasil Doutora em filosofia pela Universidade do Estado do Rio de Janeiro e estudo especialmente estética, filosofia da arte, ontologia, poéticas. Este ano, publiquei meu primeiro livro infantil, "O cabelo de Cora" lançado pela Pallas Editora.anavieirazarcocamara@gmail.com
} 
uma personagem histórica. Ao contrário dos elementos revelados pelo habitante da casa, que pertencem ao âmbito do público e exposto, temos com o museu-casa, a oportunidade de acessar o universo íntimo do morador, recriando o dado, re-colorindo os ambientes. Sob este aspecto, a casa aberta à visitação se revela como plataforma propícia a um estetizar que faz dos objetos expressões, assim como faz do visitante artista ativo do espaço íntimo.

Palavras-chave: Fenomenologia, Espaço íntimo, Museu-casa, Estética

\begin{abstract}
:
The goal of this paper is to prepare a phenomenological research, with a view to the spatiality of "historic house museums". This character is revealed through the consideration that any object has a multitude of meanings that only if limited at the moment that it enters into this relationship. Our starting point is the duplication of the object "historic house museums": as an object to the inhabitant of the house and its constructions of meaning; and as an object facing the look and visitor expectation of the house, one who scrutinizes the shifting and intangible border that separates and unites time, space and significances woven by home-resident-visitor relationship.

It is known that it is impossible to reconstruct with absolute and unquestioned loyalty the "aura" of the house of former times. The absence of residents and the spatio-temporal displacement are some of the factors that prevent a direct look at the house per se. What differentiates the "historic house museums" of other museums and stimulates the visitor, a peculiar receptivity, namely the curiosity to know, although displaced from their space-time and move themselves, the secret spaces of a historical character. Unlike the elements revealed by the inhabitant of the house, which belong to the scope of the public and exposed, we have with the "historic house museums", the opportunity to access the intimate universe of the inhabitant, recreating the data, re-coloring environments. In this regard, the house open to visitors is revealed as favorable platform to a aestheticize that makes objects expressions, as does the visitor active artist intimate space.
\end{abstract}

Keywords: Phenomenology, intimate space, "historic house museums", Aesthetics 
"Cheio de méritos, é no entanto
poeticamente que o homem
habita esta terra".

Hölderlin

Como se faz entrever seu título, o objetivo desta comunicação é empreender uma abordagem fenomenológica do museu-casa. Devido, sobretudo, aos inúmeros sentidos em que o termo "fenomenologia" vem sendo empregado ao longo da história das idéias, cabe a nós, inicialmente, esclarecer o que, no presente estudo, representará o recurso a uma investigação de cunho fenomenológico.

Não serão os autores da tradição filosófica e cultural que nos orientarão nesta empreitada. Seremos guiados pela simples análise etimológica do termo fenomenologia. Muitas vezes, uma investigação das origens, mesmo etimológicas e historiográficas, ajudam-nos a compor um tom de um pensamento, duma abordagem. Não que se deva acreditar no valor em-si-mesmo das "coisas"/vocábulos ou que a História seja, como um "bom professor", douta em ensinar por exemplos. Contudo, não há nada de pernicioso em termos nos verbetes e eventos que recortamos do "ribeirinho temporal" um instrumento ou, usando o jargão dos geômetras, um "ad initio"[a-se-principiar] de uma perspectiva crítica. Tendo isto em mente, trazemos a composição de "fenomenologia" pelos seus mais essenciais elementos da língua grega: phainómenon e lógos. Phainómenon designa tudo aquilo que é passível de ser posto à luz, tudo o que é iluminado, resplandescente. Lógos, derivado do verbo légo, compreendido pela tradição como discurso, palavra ou razão, pode, porém, ser entendido, alguns passos aquém desta interpretação, simplesmente como elemento que reúne, ordena, organiza. 
Portanto, "fenomenologia" seria a busca pelo lógos do phainómenon, ou seja, a busca pelo ordenamento/colheita daquilo que é posto à luz. O ato de reunir não seria mero complemento do fenômeno, como algo que a ele se anexasse $a$ posteriori. É o lógos que possibilita que o que aparece, apareça; se desvele. Privilegiada pela imagética grega e inspiradora do termo do qual derivam lego e lógos, está o agir imanente da "colheita", o próprio do verbo legein: recolher, colher, apanhar, para colocar em abrigo. O ato de colher, de retirar do solo, não se confunde com o violento gesto do saque. Do mesmo modo, o ato de juntar que a ele se segue não pode confundir-se com simples acúmulo. Somente retiramos do solo e juntamos para abrigar, conservar, colocar em repouso, em última análise, colhemos para re-colher. Neste sentido fundamental, a colheita ou legein nos remete aos abrigo, resguardo, refúgio e recolhimento. Portanto, este ordenamento que queremos empreender ao fenômeno, ou seja, o olhar fenomenológico que sobre ele lançamos, tem menos familiaridade com as taxonomias assaz generalizantes e controladoras do saber científico, e mais afinidade com um "deixar as coisas serem", salvaguardando-as, tal qual ocorre na poíesis.

Poíesis abre-se a fabricação, produção e criação, mas não como a ação criadora e produtiva típica da práxis de um Aristóteles das ações da "ética prática" ("Ética a Nicômaco") ou "agir político"("Política"). A "criação" poética, aquilo intrínseco a "deixar as coisas serem", aproxima-se mais a adoção do apresentado em sua vigência quase encantada e originária do que aparece por si só, liberto de um aquiescimento o qual necessite, a fim de se validar, do compreender-se fora do acontecer per se. Significa o mobilismo do estético, daquilo sensitivo, da entrega extática do mevlevi ${ }^{2}$, dos passos de um

2 Dervixe rodante, o qual, na sua dança de torvelinho,"recorda o primal/Deus"[dhikr]. 
"refrigério": "Primeiro - Calafrio; depois Estupor; por fim, o deixar-se ir." ${ }^{3}$

A partir destas considerações sobre a abordagem fenomenológica, podemos então, questionar: como realizar uma fenomenologia do museu-casa? Tomar o museu-casa como fenômeno a ser salvaguardado, colhido, demanda que lancemos sobre ele uma meditação serena que busque desvelá-lo naquilo que lhe é implícito e singular, sem com isto encarcerá-lo em figurações prévias de mundo. A expressão museu encontra suas raízes primevas no vocábulo grego mouseion, que significa "templo das musas", lugar onde moram as musas, local onde as pessoas se exercitavam na poesia e na música, lugar consagrado aos estudos, biblioteca, academia. Quem são as musas que habitam o museu? Ao todo, são nove, nascidas de nove dias de núpcias de Zeus e a deusa Mnemosyne (Memória), divindade filha do céu e da terra, irmã do tempo e do oceano. O poeta, mestre da verdade, como bem apontou o helenista Detienne, não fala por conta própria. Sua poíesis é inspirada, ou seja, recebe alento, ar, das musas, que sabem tudo o que foi, é e será, devido à sua filiação com a própria Memória e, portanto, são elas, Musas, que possibilitam que a verdade (alethéia) se dê, verdade como lembrança, mas também como desvelamento, des-ocultar. Assim, o museu se apresenta como local que abriga a verdade, a Memória e a poesia, ou criação imanente de Mundo.

Tal qual a palavra mágica dos poetas gregos inspirados pelas Musas, o Museu somente se realiza na medida em que é expressão, ou seja, em que é produção (poíesis) voltada para a aisthesis (fruição). O poeta canta e encanta seus ouvintes. $\mathrm{O}$ museu, templo da poesia, somente se completa na exposição, no

\footnotetext{
33 Emile Dickinson Apud ALVAREZ, A. O deus selvagem: um estudo do suicídio. Tradução de Sônia Moreira. São Paulo: Cia das Letras, 1999, p. 259.

${ }^{4}$ DETIENNE, Marcel. Os Mestres da Verdade na Grécia Arcaica. Tradução de Luiz Roberto Salinas Fortes. Rio de Janeiro: Jorge Zahar Editor, 1988, 4a ed.
} 
que se oferece à fruição estética. Portanto, além da dimensão que aproxima sua produção da ciência (enquanto ordenamento racional, imposição de regras e taxonomias rígidas), há, quando tratamos do museu, uma outra dimensão, desta feita, vinculada à sua vocação estética, plenamente realizada quando do encontro entre museu e visitante.

A ciência pode classificar e nomear os órgãos de um sabiá Mas não pode medir seus encantos.

A ciência não pode calcular quantos cavalos de força Existem

Nos encantos de um sabiá.

Quem acumula muita informação perde o condão de adivinhar: divinare.

Os sabiás divinam. ${ }^{5}$

O museu, tal qual o poeta e o sabiá cantado na poesia de Manoel de Barros, encanta, ou divina. Tal poder divinatório e encantatório se realiza de forma singular no museu-casa, espécie peculiar de museu que traz consigo características próprias, que não devem ser negligenciadas. Em primeiro lugar, o museu-casa é uma espécie de teatro

(lugar de onde se vê; espetáculo) de objetos. Tais objetos, ordenados à luz de uma temporalidade fugidia, recebem desta ordenação ou lógos seu traço relacional. Não se tratam de objetos estanques, imóveis, ou que se definem pela mera instrumentalidade. Estes objetos, alocados segundo inspiração das Musas, filhas da Memória, formam um cenário, um espaço cênico, em constante remissão àquele(s) que teria(m), em outro momento habitado a casa.

Em segundo lugar, o museu-casa nos remete a um tempo-espaço de múltiplas camadas, de infinitas dimensões, exatamente porque o tempo da poíesis não se confunde com o

${ }^{5}$ BARROS, M. Livro sobre nada. Rio de Janeiro, Record, 2000, p. 53. 
tempo cronológico, mensurável, sucedâneo. Diferentemente do tempo ordinário da vida, que corre, horizontalmente, o tempo poético jorra, em sua verticalidade fundamental.

Enquanto todas as experiências metafísicas são preparadas por intermináveis prólogos, a poesia recusa preâmbulos, princípios, métodos, provas. Recusa a dúvida. No máximo tem necessidade de um prelúdio de silêncio. De início, batendo em palavras ocas, faz calar a prosa ou os trinados que deixariam na alma do leitor uma continuidade de pensamento ou de murmúrio ${ }^{6}$.

Isto porque enquanto no tempo prosaico estamos nos domínios da palavra unívoca e monosignificante, a palavra do tempo poético nos leva à imagem, da mesma forma que os objetos do museu-casa: poeticamente, nos fazem habitar numa temporalidade orientada pelas sensações, memórias e por blocos de imagens. Daí podermos afirmar, sem pudores, dentro de um museu-casa, que estamos no hoje e no ontem; estamos num museu, na casa da personagem histórica, e/ou em nossa casa natal e/ou onírica. Uma simples visita a um jardim pode nos levar ao sentimento da primavera absoluta, sem contornos definidos que indiquem de qual primavera se trata, de que ano, se em Paris do século XVIII, no Japão do século III ou em algum quintal do interior de Minas Gerais na década de 1950. Esta imagem instantânea que se oferece a nós em bloco - que nos dá uma estação absoluta - não pode ser analisada objetivamente, ou seja, dela não podemos retirar e discernir os elementos constitutivos, da mesma forma em que não é possível

\footnotetext{
${ }^{6}$ BACHELARD, G. "Instante poético e instante metafísico" in O direito de sonhar. Tradução de José Américo Motta Pessanha, Jacqueline Raas, Maria Lúcia de Carvalho Monteiro e Maria Isabel Raposo. Rio de Janeiro: Bertrand Brasil, 1994, p. 183.
} 
experimentar os afetos de um outro corpo com o auxílio de um bisturi.

Em terceiro lugar, este espaço cênico que nos situa nas dobras do tempo e nas regiões fronteiriças das paisagens oníricas, demanda a visita de um sujeito em tudo diverso do modelo cartesiano que serve, ainda hoje, de paradigma da ciência. Tal modelo, fornecido pelas ciências, exige um sujeito acabado, frio, invulnerável à ação de seu objeto de investigação. Este sujeito é pura atividade prática, diante de objetos retirados de seus cenários, partículas mutiladas de sua totalidade, meros receptáculos de categorias e figurações de mundo previamente estabelecidas e universalizantes. Mas, como afirma Michel Serres:

Não se pode falar de espécie, indivíduo, fato, paisagem, proteína ou estrela de maneira genérica; o singular não pode ser compreendido por meio de idéias gerais. Todos são únicos e sujeitos a inúmeras circunstâncias. Só podemos descrevê-los, esboçá-los, copiá-los, reproduzi-los ou representá-los; em resumo, imitá-los ponto a ponto, detalhe por detalhe. A arte da cópia propicia o conhecimento dessa singularidade. A justo título, a memória, como uma soma das cópias, agora é considerada como único conhecimento. Por sua vez, também as memórias, os objetos inertes ou técnicos, os corpos vivos, o mundo, vivem, enfim, sua condição de suportes ou sujeitos. ${ }^{7}$

Ao entrarmos no museu-casa, nos é feito um convite para tomarmos cada objeto, cada detalhe, cada memória corporificada, não de forma ativa, como a preconizada pela ciência, mas apaixonadamente. No seu revelar, compõe-se um singular pathos(paixão, conjuntura), o ato de juntar con-

\footnotetext{
${ }^{7}$ SERRES, M. Variações sobre o corpo. Tradução de Edgard de Assis Carvalho e Mariza Perassi Bosco. Rio de Janeiro: Bertrand Brasil, 2004, p. 81.
} 
juntamente, bailado entre o objeto que se abre ao recolhimento e o sujeito, disposto a se perder no objeto. Aqui, não se quer conhecer para controlar, mas corremos o risco, tal qual o objeto, de não mais nos reconhecermos, de sairmos da experiência sem referenciais, sem garantias, menos certos acerca de nós próprios e do mundo. Somos, neste instante de poíesis, sujeitos encarnados, singulares, incomparáveis, implicados no objeto inclassificável, resistente a quaisquer categorizações. No encontro destes fluxos de intensidades, toda previsibilidade é descartada. Ninguém - nem mesmo os organizadores do acervo - poderia atinar o que aí se produz, em termos estéticos, afetivos, mnemônicos e imaginários. O objeto, tomado de significados, se mostra em sua singularidade a um sujeito - não o visitante $X$ ou $Y$, ou o nome assinado do livro de visitas - mas a um sujeito encarnado, dotado de repertório inacabado e, ainda assim, infinito de emoções, lembranças e imagens íntimas, por vezes inconfessáveis até a si mesmo.

Em um museu-casa esta comunicabilidade entre sujeito e objeto se dá de forma ainda mais intensa do que ocorreria em outros tipos de museu. A imagem da casa, imagem primitiva e arquetípica aos olhos do filósofo francês Gaston Bachelard, é dotada de grande força imaginária, mergulhando-nos nos profundos domínios do devaneio. Tal qual a imagem da gruta, do ventre materno ou da concha, a imagem da casa nos direciona a uma dimensão poética da intimidade, do ensimesmamento, do repouso.

Este ensimesmamento plenamente representado pela imagem da casa se manifesta no universo imagético-mitológico da cultura grega clássica, através da deusa Héstia, deusa anônima que não encontra, nesta cultura, nenhum tipo de representação iconográfica, já que ela é a própria lareira (estía), seja ela lareira-mandala, lareira da casa, da Grécia, chegando a receber o estatuto de fonte de calor do universo, numa projeção do microcosmos (casa) no macrocosmos. Diferentemente do que 
ocorre com as demais divindades, não encontraremos de Héstia estatuário ou pintura confeccionados no período clássico, devido à sua presença, onipresente, por todos os espaços citadinos, como o fogo que ao mesmo tempo que queima, aquece. Voluntariamente isolada da agitação característica dos dramas e conflitos dos deuses olímpicos, a virginal Héstia mantinha-se fixada silenciosamente no Olimpo. Seu silêncio e sua fixidez não a impedem de participar de todas as fases da vida de um cidadão grego. É sob sua lareira que, na mais tenra idade, o grego é purificado. É este mesmo fogo bailante e purificador que consome este corpo, já sem vida. O domínio dos interiores, do espaço privado, destinado à deusa Héstia, é o espaço mesmo do feminino, alegremente colocado à parte de toda a discussão e polêmica próprias à esfera do público, das praças e mercados. Esta matriz feminina, fonte de calor e conforto, não se compadece por se ausentar do âmbito da política e dos negócios. Ela quer o silêncio, a quietude, os murmúrios cantantes que acompanham, ritmicamente, as pequenas tarefas do dia-a-dia, aquelas tarefas sem as quais nenhuma outra é possível. $\mathrm{Na}$ discrição de seus pequenos gestos, Héstia prepara o cenário propício para os inebriantes devaneios:

Um sonhador de lareira não pode se enganar: o mundo do calor é o mundo da doçura generalizada. $\mathrm{E}$, para um sonhador de palavras, o calor é realmente, em toda a profundidade do termo, o fogo no feminino ${ }^{8}$.

Independentemente da época, das circunstâncias históricas ou sociais, das condições econômicas, guardamos, como que numa memória do corpo, as sensações de proteção de

\footnotetext{
${ }^{8}$ BACHELARD, G. A poética do devaneio. Tradução de Antonio de Pádua Danesi. São Paulo: Martins Fontes, 1996, p. 186.
} 
nossa tenra infância, como sensações privilegiadas e reconfortantes. O homem é um animal que habita, que ocupa um espaço e dá a ele o sentido de um lar. Às aves, seu ninho; aos ursos, sua caverna; aos homens, sua casa. Sejamos nômades, viajantes, aventureiros sem rumo e sem pátria, escolheremos, nem que seja um pedaço da rua, um banco de praça, uma cabana, como refúgio: contra o frio, mas também contra os perigos que a noite ameaça trazer, não só efetivamente, como também em nosso imaginário. Existe perigo maior do que aquele que ameaça a segurança da casa? Daí a literatura e a filmografia serem repletas de referências à casa mal-assombrada, à casa que não obteve sucesso em sua função primordial de proteção e abrigo. Vale ressaltar que, diferentemente do reino do conceito e do rigor, em que o sucedâneo garante o sucesso das redes de causalidade, no reino do devaneio poético o instante garante a simultaneidade das ambivalências. No território mágico da imagem, o lugar do abrigo é o mesmo da armadilha; o lugar da vida é o mesmo da morte. Os terrores suscitados pela casa simples são detalhadamente descritos no conto "A estampa da casa maldita", de Lovecraft:

Os amantes do horror freqüentam sítios estranhos e remotos. Nada desejam senão as catacumbas dos Ptolomeus e os mausoléus esculpidos dos países de pesadelo. Sobem às torres enluaradas das ruínas de castelos dos Reno, descem negras escadarias, cobertas de teias de aranha, sob as pedras dispersas de esquecidas cidades da Ásia. (...) No entanto, o verdadeiro epicurista do horror, para quem uma desconhecida palpitação de inenarrável pavor constitui a finalidade maior e justificativa da existência, estima antes de tudo as fazendas antigas e solitárias do interior da Nova Inglaterra. Pois é ali que os soturnos elementos de força, solitude, grotesco e ignorância se combinam para moldar a quintessência do tétrico. Dentre tudo quanto ali se vê, o mais 
hediondo serão as casinhas de madeira, sem pintura, distantes dos caminhos mais batidos, em geral agachadas sobre uma encosta úmida e relevosa ou encostada em algum gigantesco afloramento rochoso. Há duzentos e tantos anos estão ali encostadas ou agachadas, enquanto as lianas lançaram-se cada vez mais longe e as árvores incharam e se espalharam. Acham-se agora quase escondidas entre luxuriâncias desordenadas e verde e entre mortalhas guardiãs de sobras; mas as janelas de pequeninas vidraças ainda fitam o vazio chocantemente, como se pestanejassem num estupor de morte que repele a loucura ao embotarem as recordações de coisas indizíveis ${ }^{9}$.

Quando estamos em situação poética, diante dos cenários do museu-casa, este espaço cênico faz proliferar em nós uma mistura, verdadeira endosmose, entre os devaneios e as lembranças. Temos enraizadas em nosso íntimo imagens acolhedoras de nossa casa natal, que, ao serem reativadas, já não se restringem a simples memórias, mas ganham novos contornos oníricos e, neste ponto, já não somos capazes de responder se trata-se de lembrar ou imaginar.

Sonhamos com o que foi, mas também com o que poderia ter sido, em nossas casas e na casa que agora visitamos. Os objetos mágicos e encantatórios do museu-casa, independentemente de seu tamanho, período, ou sofisticação, assim como seus odores, texturas e atmosfera, não possuem, para o visitante estético, função meramente informativa, ou historiográfica. Não se trata de receber dados sobre a casa, seus moradores e sua época. Arrebatados pelo poder cênico dos ambientes, somos imediatamente mergulhados em infinitos mundos possíveis, muitas vezes abertos, tal qual portais, por objetos simples, micro-objetos cotidianos, que em outras

9LOVECRAFT,H.P. "A estampa na casa maldita” In Um sussurro nas trevas. São Paulo: Francisco Alves, s.d., p.1. 
circunstâncias, não representariam potencial imagético algum. Estes objetos, de extrema utilidade outrora, hoje se caracterizam pela "desutilidade poética" tão enaltecida pelos poemas de Manoel de Barros. O objeto, no museu-casa, é inútil propositadamente, já que o uso das coisas é inversamente proporcional à sua conservação. Portanto, pretende-se que tais objetos, não mais usados, mas contemplados, guardem na medida do possível, as mesmas características e propriedades do passado. Preferencialmente, queremos o máximo de fidelidade também no que diz respeito à sua disposição espacial. Porém, a conservação material e espacial do objeto não é, de forma alguma, obstáculo, para que tal objeto evoque de forma absolutamente instável um passado que conjuga harmonicamente o "era uma vez" com o "como se fosse":

Examinado nessas dialéticas, o passado não é estável; ele não acode à memória nem com os mesmos traços, nem com a mesma luz. Apenas se vê apanhado numa rede de valores humanos, nos valores da intimidade de um ser que não esquece, o passado aparece na dupla potência do espírito que se lembra e da alma que se alimenta de sua fidelidade. A alma e o espírito não têm a mesma memória. ${ }^{10}$

Trata-se aqui da distinção, feita por Bachelard, entre dois tipos de memória: uma vinculada ao animus ou espírito, que organiza racionalmente o mundo e os eventos, e outra, proveniente da anima, alma que prepara um mundo imageticamente articulado, portanto sempre dinâmico, ainda que enraizado nas noturnas e obscuras fontes inconscientes. Enquanto a memória de animus encadearia fatos e contaria a história dos acontecimentos e das existências, a memória de

10 BACHELARD, G. A poética do devaneio. Tradução de Antonio de Pádua Danesi. São Paulo: Martins Fontes, 1996, p. 99. 
anima desceria a uma camada mais profunda do que a factual: se dirigiria aos valores de nossa intimidade. Tais valores não podem ser contados por nenhuma outra pessoa, somente por nós mesmos, traduzindo ao máximo nossos espaços secretos. Ao cofre, ao fundo falso, à gaveta trancada com chave de ferro antiga, à passagem secreta tão viva nos filmes de suspense, ou seja, aos espaços secretos da casa, correspondem, em nós, estes valores, documentos sem data arquivados em nosso psiquismo mais fundante.

Ao encontrar com os objetos que revelados, ainda secretam a intimidade de uma personagem histórica, o visitante do museu-casa se sente tentado a perscrutar seus mistérios. Tais mistérios possuem uma hierarquia, isto é, podemos dizer que a casa guarda grandes e pequenos segredos, da mesma forma que ocorre na casa habitada. Nesta última, a intimidade da roupa íntima não demanda a mesma "engenharia do esconderijo" que um diário ou mesmo uma jóia de família, passado presentificado. $\mathrm{Na}$ casa que se tornou museu, o campo do secreto se expande. Somente pela imaginação, entrelaçada à memória, pode-se reencenar integralmente alguns "sentires" da casa. Se ainda temos acesso ao cheiro de madeira do corrimão das escadas e das tábuas do piso, não podemos dizer o mesmo das lavandas que perfumaram os lençóis; das especiarias que anunciavam festas e banquetes; dos charutos, ao mesmo tempo fortes e doces, marcadores privilegiados da presença masculina.

Da mesma forma se escondem os sons: qual seria o som dos sapatos femininos subindo as escadas ou correndo em direção à porta? E as músicas que ali se ouvia? Que ritmos e sonoridades testemunharam as disposições de espírito daqueles moradores, intercalando solidões e visitas, dias e noites? Infinitas possibilidades se abrem ao visitante a partir da simples contemplação dos objetos singelos do museu-casa. Como no labirinto, em que a emoção acaba assim que a saída se revela, os jogos de luz e sombra, de aberto e fechado, de público e privado 
dos museus-casas, somente encantam e fazem sonhar pela impossibilidade de uma revelação definitiva. É nesta impossibilidade que se ancora a oportunidade de sermos levados para fora do tempo crônico, e convidados a pintar com tons ainda inexplorados a intimidade da personagem histórica, que assim como a nossa, desvela no simples e no comum sua maior riqueza.

\section{REFERÊNCIAS BIBLIOGRÁFICAS}

ALVAREZ, A. O deus selvagem: um estudo do suicídio. Tradução de Sônia Moreira. São Paulo: Cia das Letras, 1999.

BACHELARD, G. "Instante poético e instante metafísico"in $O$ direito de sonhar. Tradução de José Américo Motta Pessanha, Jacqueline Raas, Maria Lúcia de Carvalho Monteiro e Maria Isabel Raposo. Rio de Janeiro: Bertrand Brasil, 1994.

BACHELARD, G. A poética do devaneio. Tradução de Antonio de Pádua Danesi. São Paulo: Martins Fontes, 1996.

BARROS, M. Livro sobre nada. Rio de Janeiro: Record, 2000.

DETIENNE, Marcel. Os mestres da verdade na Grécia arcaica. Tradução de Luiz Roberto Salinas Fortes. Rio de Janeiro: Jorge Zahar Editor, 1988, 4a ed.

LOVECRAFT,H.P. "A estampa na casa maldita" in Um sussurro nas trevas. São Paulo: Francisco Alves, s.d.

SERRES, M. Variações sobre o corpo. Tradução de Edgard de Assis Carvalho e Mariza Perassi Bosco. Rio de Janeiro: Bertrand Brasil, 2004. 
